\title{
ES UN MUNDO PEQUEÑO: MOVILIDAD Y REDES EMPRESARIALES EN EL PROCESO DE COLONIZACIÓN AMERICANA
}

\author{
CARMEN MENA GARCÍA \\ Universidad de Sevilla ${ }^{\mathrm{a}}$ \\ MONTSERRAT CACHERO VINUESA
}

Universidad Pablo de Olavide ${ }^{\mathrm{b}}$

It's a Small World:

Spatial Mobility and Business Networks in the Latin America

Colonization Process

\begin{abstract}
This paper analyses economic interaction in Castilla del Oro (Panama) at the beginning of the $16^{\text {th }}$ century. By applying network analysis to fiscal records, the paper reconstructs, represents and tests business networks in the mining sector and how they became more complex with the arrival of emigrants and the appearance of new gold deposits. Results show a dynamic population with a high mobility degree despite the adverse geography and the inexistent communications.
\end{abstract}

Keywords: Network Analysis, Geography, Mining, 16th Century, Panama

JEL Classification: N56, N96, D85

\footnotetext{
a Departamento de Historia de América. cmena@us.es

b Departamento de Economía, Métodos Cuantitativos e Historia Económica. mcacvin@upo.es
} 


\section{RESUMEN}

El presente artículo analiza la interacción económica en la gobernación de Castilla del Oro (Panamá) a principios del siglo XVI. La riqueza de las fuentes analizadas permite reconstruir, representar y medir las redes empresariales en torno al negocio minero y cómo se vuelven más complejas con la llegada de inmigrantes y la aparición de nuevos yacimientos. Los resultados muestran una población increíblemente dinámica con un elevado grado de movilidad a pesar de las dificultades geográficas y las inexistentes comunicaciones.

Palabras Claves: Análisis de Redes, Geografía, Minería, Siglo XVI, Panamá

\section{INTRODUCCIÓN}

Mucho se ha escrito sobre el proceso de conquista y posterior colonización del continente americano. En especial, la figura de los denominados conquistadores ha centrado la atención de numerosos estudios históricos. Generalmente encasillados en su papel de individuos con sed de oro y grandezas, se ha asumido que la actividad desempeñada por este colectivo se encaminó exclusivamente hacia la búsqueda de tesoros y el sometimiento de la población indígena. Si bien es cierto que la búsqueda de metales preciosos actuó como pull factor en el proceso de expansión colonial, también lo es que en aquellas zonas donde se descubrían yacimientos, el grupo de los denominados conquistadores desarrollaron una intensa actividad empresarial. La documentación de archivo muestra a estos individuos formando compañías, reclutando cuadrillas de mineros, importando el material necesario para poner en funcionamiento el negocio del oro, firmando contratos, y fundiendo el mineral extraído. Y es que, en el continente americano las expediciones de descubrimiento y conquista fueron siempre complementarias al despliegue de todo tipo de tareas destinadas al empeño empresarial (Lohmann Villena 1968, Varón Gabai 1989 y 1994, Otte 2004). ${ }^{1}$

En este artículo se reconstruye la actividad económica desempeñada por los primeros europeos en América continental. En concreto, aplicamos el análisis de las redes para estudiar las interacciones en torno al sector minero en la gobernación de Castilla del Oro, desde sus inicios hasta

\footnotetext{
1 Entre las referencias de historiografía al respecto podemos estacar el trabajo de Rafael Varón Gabai (1989 y 1994) sobre los negocios de la familia Pizarro durante la conquista del Perú, el análisis de Enrique Otte (2004) sobre las pesquerías de perlas de Diego Caballero y de Lohmann Villena (1968) sobre los Espinosa.
} 
1526. A pesar de tratarse de los primeros asentamientos europeos en la América continental, el territorio y la época analizados han resultado marginados por la historiografía hasta muy recientemente. ${ }^{2}$ La importancia de estas ciudades radica en su papel como plataformas de expansión hacia otros territorios más ricos y atractivos. Además, constituyeron el germen de experimentación en cuanto a fórmulas de gobierno local, relaciones con la población indígena o rentabilización de recursos naturales.

Se trata de enclaves en zonas selváticas, escasamente poblados y con condiciones de vida extremas. Esta escasez de población europea junto el aislamiento geográfico alimentaba complejas y cambiantes dinámicas de grupo permitiendo un elevado grado de conexión interpersonal. En este universo de intrincadas relaciones analizamos la actividad en torno al sector de la minería del oro, en concreto nos preguntamos: ¿quiénes intervenían en el negocio minero? ¿Qué tipo de vínculos existía entre ellos? ¿Cómo eran estas relaciones, duraderas o cambiantes? ¿Respetaban la exclusividad que exigía el negocio empresarial o, por el contrario, imperaba la movilidad inter-grupos? ¿Aplicaron algún tipo de estrategia o criterio para la selección de las cuadrillas? ¿Eran éstos similares a los que imperaban en Europa? ¿Qué variables explicaron el éxito en el sector estudiado?

Para dar respuesta a estas cuestiones se usaron los registros de los Oficiales Reales para las tres casas de fundición de la provincia en sus primeros años. Estudiamos, en concreto, los apuntes correspondientes a Santa María de la Antigua del Darién y Acla en la costa Atlántica, y Panamá en la franja del Pacífico, que son los principales asientos poblacionales del territorio. ${ }^{3}$ Los primeros apuntes datan de 1514 y se corresponden con la casa de fundición de oro de Santa María, cuyos registros se prolongan hasta la desaparición de la ciudad en 1524. La actividad registrada en Acla comienza en 1525 y se prolongará hasta mediados del siglo XVI. ${ }^{4}$

\footnotetext{
${ }^{2}$ Este primer periodo de la minería aurífera en la Tierra Firme despertó el interés de historiadores como Hermes Tovar (1999) y especialmente Carmen Mena que en su obra El Oro del Darién (2011a) realiza un análisis exhaustivo de las explotaciones mineras y las redes empresariales en el citado territorio. Para el marco espacial e histórico debe citarse a Celestino Arauz Monfante (1991) (2006) y el trabajo compilatorio de Castillero Calvo en su enciclopedia de cinco volúmenes sobre la Historia de Panamá -véase Castillero Calvo (2004). Además cabe destacar las aportaciones de Mario Góngora (1961), Mena (1984), García Casares (2008), Aram (2008), Becerra y Vignolo (2011) o Alzate Gallego (2011), recientemente Mena (2011b) (2015).

${ }^{3}$ Tal y como se explica en el siguiente apartado dividimos el territorio estudiado en dos regiones: Darién en la costa atlántica y Panamá en el Pacífico. La región del Darién comprende las casas de fundición en las poblaciones de Santa María de la Antigua y Acla y, el área del Pacífico comprende la casa de fundición de Panamá. En el espacio de tiempo estudiado los individuos tenían libertar para declarar y fundir mineral en aquella casa de fundición que libremente eligiesen, que normalmente era la más cercana al yacimiento.

4 Tanto en Acla como en Panamá nos limitamos al estudio de dichos apuntes contables hasta 1526, fecha en la que Santa María de la Antigua desaparece por completo.
} 
Mayor progresión temporal presentan los apuntes en la casa de fundición establecida en Panamá en 1521, tan sólo dos años después de la fundación de la ciudad. El desplazamiento de la capitalidad de la gobernación de Castilla del Oro desde Santa María de la Antigua hasta Panamá, decretado por el gobernador Pedrarias Dávila en 1519, forzó el traslado de todas las instituciones de gobierno y, con ello, de la élite política y económica. La escasa población del territorio se movilizó hacia la costa del Pacífico atraída por una favorable política de reparto de tierra y concesión de encomiendas. Son estas dos decisiones políticas las que explican que la ciudad de Panamá desde el mismo momento de su fundación se convirtiera en polo de atracción para los habitantes del istmo. Analizamos los registros anotados en la caja real de Panamá para el periodo de 1521 a 1526.

Los apuntes contables sobre las declaraciones de oro en el territorio constituyen una fuente de valor incalculable para reconstruir las conexiones entre individuos. Los datos de carácter anual identifican a los vecinos que registran mineral, sus profesiones y cantidades depositadas. Las relaciones entre los agentes implicados en el sector minero se establecen en forma binaria, obviando todos aquellos apuntes donde se declara mineral de forma individualizada. Se combinan datos biográficos de los agentes de la red junto con el cálculo de parámetros fundamentales, tales como centralidad, densidad, relevancia o intermediación.

Desde el punto de vista metodológico, el artículo parte de la teoría de redes aplicada. ${ }^{5}$ Las redes representan no sólo estructuras sino procesos de cambio en el tiempo y en el espacio y es precisamente ésta su utilidad como herramienta de análisis en una sociedad tan dinámica como la que nos ocupa, alejada de las normas de ascenso y los protocolos del viejo continente. La aplicación del análisis de redes permite observar con detalle cómo interaccionan los individuos en el periodo estudiado y describir dinámicas de grupo, modelos de liderazgo, criterios de elección de agentes, particiones y rotación laboral en el sector de la minería. Los datos estudiados muestran un sector dinámico, con elevado grado de movilidad en el espacio y en el tiempo, donde las estrategias de promoción social, que en Europa llevarían décadas, se hacen efectivas de un año a otro.

El artículo está organizado como sigue. En la primera sección se analiza el territorio estudiado con especial énfasis en la descripción de las comunicaciones. La segunda sección describe las fuentes usadas explicando con detenimiento las limitaciones de las mismas. En la tercera sección se profundiza en el estudio de las pautas de interacción entre los

\footnotetext{
5 Fue Jacob Moreno el primero en usar la teoría de redes para estudiar las relaciones sociales en 1934 pero tenemos que esperar hasta los años 70 para encontrar un aparato teórico para el estudio de las Redes Sociales. Para más información a este respecto véase Freeman (2004), Molina (2005) o Crovi Druetta, López Cruz y López González (2009).
} 
agentes implicados, analizando aspectos relevantes como la rotación laboral, la exclusividad o la pertenencia a un grupo. La cuarta sección está dedicada al estudio de los distintos modelos de liderazgo observados en los datos. La última sección recoge las conclusiones.

\section{LA FIEBRE DEL ORO: EL DARIÉN O LA GEOGRAFÍA ADVERSA}

Aunque desde fecha muy temprana hubo en Latinoamérica explotaciones de cobre, depósitos de esmeraldas e incluso fructíferas pesquerías de perlas, ninguna de ellas alcanzó la importancia de la minería del oro y la plata a cuyo alrededor giraría una parte fundamental de la economía americana. Los primeros experimentos en el sector minero se corresponden con la etapa de colonización inicial centrada sobre todo en las Antillas y la franja caribeña. Aunque con rendimientos inferiores a los esperados, este primer ciclo del oro constituyó el motor para expediciones a lo que se denominó Tierra Firme en busca de metales y población indígena para emplear en el trabajo en las minas (Chaunu 1955-1959, Haring 1979, Vila 1974).

Resultado de este proceso expansivo fue el primer asentamiento colonial en territorio continental. Santa María de la Antigua, el reino de Vasco Núñez de Balboa, fundado en 1510, constituyó un lugar estratégico por el hallazgo de alimentos en abundancia y mano de obra indígena. ${ }^{6}$ Este primer enclave castellano dominaba la región del golfo de Urabá, hacia el oeste se alzaba la serranía del Darién y la cuenca del gran río Atrato, que constituía una adecuada vía de penetración de algo más de cien kilómetros hacia el interior. Resultaba sin duda el lugar adecuado como punto de partida en las exploraciones de los territorios colindantes.

Las condiciones de vida para la población castellana, sin embargo, eran duras. La elevada pluviosidad, el grado de humedad y la densidad de la vegetación favorecían la rápida difusión de epidemias y enfermedades. Crónicas y cartas de la época describen el asiento de Santa María como "enfermiza y pestífera" o "tierra muy húmeda e llena de ciénagas de que salen muy gruesos vapores e muy enfermos". ${ }^{7}$ Tan sólo el hallazgo de oro fluvial justificó la presencia castellana en la zona. En 1514 el capitán Vasco Núñez de Balboa afirmaba en su carta al rey que "en esta provincia del Darién, donde hay descubiertas muchas y muy ricas minas hay oro en cantidad... de casa de este cacique Dadaiba viene todo el oro que sale por

\footnotetext{
${ }^{6}$ Sobre las razones para la elección del emplazamiento de esta primera ciudad véase Casas (1957), Vol. II, p. 273.

7 En estos términos se describe el territorio en la crónica de Pedro Mártir de Anglería, véase Anglería (1989), pp. 87 y siguientes.
} 
este golfo y todo lo que tienen estos caciques de estas comarcas; es fama que tienen los caciques de oro piezas extrañas y muy grandes señalan los indios que son del tamaño de naranjas y como el puño".

No muy lejos de Santa María de la Antigua, entre 20 y 40 leguas de distancia, en dirección noroeste, se encontraba la población de Acla (Bahía de Aglatomate). ${ }^{9}$ Fundada en 1516 sobre un asentamiento indígena, este modesto enclave costeño se comunicaba a duras penas con Santa María de la Antigua a través de un agreste sendero a través de la selva (Mena 2011a, p. 42).

El último de los enclaves poblacionales estudiados es el de Panamá, que fue fundado algo más tarde, concretamente en $1519 .{ }^{10}$ Originariamente la ciudad no era más que un poblado de indígenas dedicados a la pesca, el mismo gobernador Pedrarias Dávila relataba como "hay mucha sardina, que es pescado de que el pueblo se mantiene, e que los días de pescado todo lo que montaban lo llevaban a la playa y allí se repartía por todo el pueblo de balde, que era muy gran bien e ayuda para todos los pobladores porque de otra manera no tendrían que comer". ${ }^{11}$ El descubrimiento de oro de río en la zona planteó la necesidad de establecer un nuevo asiento donde declarar y fundir el mineral. En 1521, tan sólo dos años después de su fundación se estableció la casa de fundición de Panamá para que los señores de minas de la costa del Pacífico pudieran registrar su oro sin necesidad de desplazarse hacia Santa María de la Antigua.

\subsection{Barreras Físicas y Movilidad Espacial}

Una de las características más sorprendente de la población analizada es su dinamismo, tanto social como geográfico. Si bien la movilidad social es fácilmente deducible, resulta bastante más complejo explicar la movilidad a nivel geográfico. La pluvioselva tropical, el relieve irregular, las condiciones climatológicas y la inexistencia de vías que comuniquen unas zonas con otras hacían de la movilidad humana una tarea en apariencia imposible. A pesar de lo expuesto, una parte considerable de la

\footnotetext{
${ }^{8}$ Carta de Vasco Núñez de Balboa a S.M., Santa María de la Antigua, 20, enero, 1513. Archivo General de Indias de Sevilla (en adelante AGI), Patronato, 26, R. 4.

${ }_{9}$ Las fuentes contemporáneas difieren al respecto. Oviedo asegura que Acla se encontraba a 20 leguas de distancia de Santa María de la Antigua, mientras que Pascual de Andagoya incrementa la distancia hasta unas 40 leguas. Cfr. Mena (2011a, p. 207, nota 176).

10 Sobre la fundación de Panamá se acusó al gobernador Dávila del abandono de Santa María del Darién. «Por verse Pedrarias libre de los del Darién, fundó a Panamá contra la voluntad de los españoles», señalaba una denuncia anónima en aquellos días. Véase «Relación sobre el gobierno de Pedrarias y sus expediciones sacada del Archivo de Simancas», en Colección Muñoz, tomo 75, fols. 300-304.

11 Real Cédula al licenciado Antonio de la Gama, Ocaña 4 de abril de 1531. AGI, Panamá, 234, L 2, ff. 131-134. Véase Mena García (1992, p. 37).
} 
población se trasladaba de forma continua de un extremo a otro, de la costa del Pacífico al Caribe, cruzando ríos y atravesando zonas selváticas.

La primera dificultad para fijar en un mapa los rudimentarios caminos, más bien sendas, que enlazaban estas poblaciones se relaciona con la existencia de las necesarias huellas arqueológicas. Y es que aunque localizar la antigua ciudad de Panamá no representa un problema, dado que el sitio se ha conservado, el resto de los asentamientos españoles del primer Darién, concretamente Santa María de la Antigua y Acla, fueron progresivamente abandonados y engullidos por la selva. En concreto, han transcurrido varios siglos hasta que los arqueólogos han logrado ubicar con exactitud el enclave en el que se alzó Santa María de la Antigua. ${ }^{12}$ En su lugar, hoy en día sólo quedan un pequeño caserío, una capilla y algunos potreros que registran una actividad mínima. Respecto a Acla o Careta, igualmente desaparecida, se supone que estaría situada en lo que hoy es el poblado de Sasardi-Mulatupu en la provincia panameña de Kuna Yala.

El siguiente mapa parte de Google Earth. Para trazar los caminos se ha tenido en cuenta la orografía de la zona, las cuencas de los ríos y los senderos potenciales. Las líneas discontinuas indican que no se trata de una vía de comunicación exacta sino aproximada.

MAPA 1

TERRITORIO Y MOVILIDAD

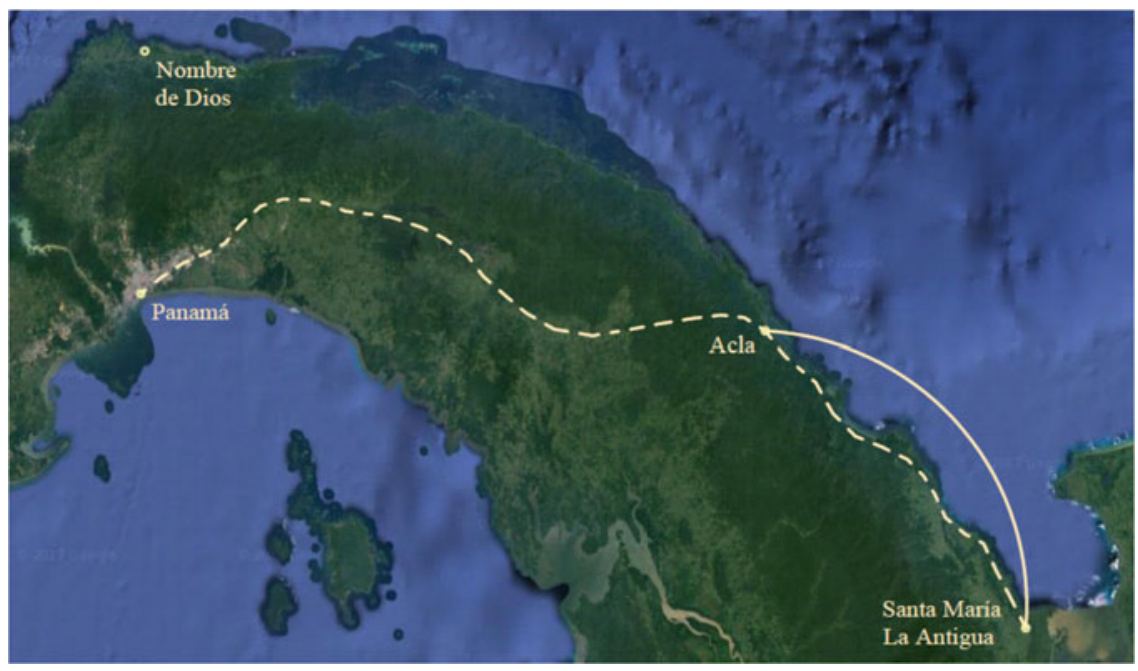

Fuente: Datos de Google Earth.

12 Los primeros trabajos arqueológicos en la zona fueron financiados por el monarca Leopoldo III de Bélgica en 1956. Posteriormente el antropólogo colombiano Graciliano Arcila Pérez señaló 
Nótese las dificultades del tránsito por esta boscosa región. Ni siquiera en la actualidad han podido resolverse pues la gran carretera panamericana que conecta la mayor parte de los países del continente se interrumpe precisamente en el conocido como el "Tapón del Darién". Las distancias, además, resultan impresionantes incluso en la actualidad. Unos $200 \mathrm{~km}$ en línea recta entre la antigua ciudad de Panamá y el poblado minero de Acla y otros 99,52 km para llegar hasta Santa María del Darién. El camino que originariamente recorrieron los habitantes de la zona transcurría por una zona con elevada densidad de vegetación y no se tienen noticias de su ubicación exacta, tan sólo los testimonios de la época se refieren a él como una vía "abierta a machetazos en la selva". ${ }^{13}$ Para trazar este camino en el mapa se ha tenido en cuenta la orografía de la zona, las cuencas de los ríos y los senderos potenciales. Las líneas discontinuas indican que no se trata de una vía de comunicación exacta, sino aproximada.

La comunicación entre Santa María de la Antigua y Acla podía realizarse por tierra o por mar, tal y como se muestra en el mapa. La comunicación por mar entre ambos enclaves resultaba mucho más rápida y menos fatigosa, sin embargo, al tratarse de un lugar interior Santa María distaba $7,5 \mathrm{~km}$ de la costa, y el punto más cercano era el Puerto de Misas. A pesar del aislamiento, de la densa vegetación y la dificultad del camino, durante el periodo estudiado la población se movilizó de forma constante. Y es que una de las características más asombrosas del grupo de análisis es, como ya dijimos, su elevado grado de movilidad, tanto social como geográfica. De hecho, los datos estudiados indican cómo en numerosos casos los individuos tributaban simultáneamente en las Cajas Reales del Darién y de Panamá.

Se trata de un colectivo de 26 individuos que representan un $23 \%$ del total de la población dedicada a la minería en la zona del Darién y algo más del 14\% de todos los sujetos que tributan en Panamá. No resulta sorprendente que la mitad de los individuos mencionados declaren ser mineros de profesión, aunque tan sólo el 25\% muestra una cierta estabilidad laboral y permanecen en la misma cuadrilla. Y es que la tasa de rotación laboral es elevadísima. Los profesionales de la minería generalmente prestan sus servicios en una compañía concreta por periodos muy breves, en multitud de casos tan sólo llegan a completar el año. Una vez finalizado el periodo para el cual se le contrató, pasan a ofrecer sus

con exactitud el sitio durante expediciones arqueológicas llevadas a cabo durante las décadas de los 70 y posteriormente en los 90 . Mena (2011a, pp. 61 y ss.)

${ }^{13}$ En su hoja de servicios el capitán Gil de Montenegro afirmaba que "se hizo a manos, cavando en algunas partes e rompiendo la montaña e arboleda a fuerza de brazos, con espadas y machetes, con las mochilas de la comida a cuestas, pasando muchos ancones de mar y esteros de ríos... y con muchos peligros de las vidas por ser muchas las salvajinas malas que allí había, como eran tigres y lagartos, que se comían los hombres", AGI, Patronato, 129, R. 1. 
TABLA 1

INDIVIDUOS QUE TRIBUTAN SIMULTÁNEAMENTE EN LAS CAJAS DEL DARIÉN Y PANAMÁ

\begin{tabular}{|c|c|}
\hline Nombre & Profesión \\
\hline Pedrarias Dávila & Gobernador \\
\hline Francisco Romero & Minero \\
\hline Francisco de Ortega & Minero \\
\hline Francisco de Herrera & Escudero \\
\hline Machín de Nocedal & Minero \\
\hline Baltasar de Herrera & Minero \\
\hline Andrés de las Hijas & Minero \\
\hline Juan de Villanueva & Minero \\
\hline Bernardino Rodríguez & Minero \\
\hline Ruy Díaz & Fundidor \\
\hline Alonso de Venegas & Minero \\
\hline Juan de Ezcaray & Capitán \\
\hline Gabriel de Rojas & Capitán \\
\hline Maestre Cristóbal & Minero \\
\hline Juan Rosete & Empresario de minas \\
\hline Juan Vázquez & Minero \\
\hline Martín Martínez & Encomendero \\
\hline Juan Rubio & Encomendero \\
\hline Sebastian de Rivadeneira & Empresario de minas \\
\hline Francisco de Miranda & Minero \\
\hline Diego del Salto & Encomendero \\
\hline Juan de la Mota & Empresario de minas \\
\hline Pedro Martín Peña & Encomendero \\
\hline Gonzalo de Albacete & Minero \\
\hline Juan Jiménez & Minero \\
\hline Francisco Pesado & Empresario de minas \\
\hline
\end{tabular}

Fuente: Mena García (2011a, pp. 407-426).

Revista de Historia Económica, Journal of Iberian and Latin American Economic History 
servicios a otra compañía minera o bien se independizan y fundan un consorcio propio. El resto del grupo declara ocupaciones muy diversas, como funcionarios, soldados y encomenderos junto con otros que no la manifiestan, pero que por su dedicación podríamos considerarlos como socios capitalistas en el negocio minero.

\section{EL REGISTRO DEL ORO COMO FUENTE EN EL ANÁLISIS SOCIAL}

Las declaraciones oficiales de oro contabilizadas por los oficiales reales representan una fuente extraordinaria para el análisis de redes económicas. Los funcionarios al frente de las diversas casas de fundición eran los responsables de registrar ante la corona todo el mineral que se declaraba en su jurisdicción. Los pormenorizados apuntes contables resultan de gran importancia pues nos ofrecen una idea clara no sólo de la rentabilidad de cada región sino de las alianzas y relaciones económicas entre la población dedicada al sector minero.

En este artículo se analizan las fuentes correspondientes a los registros de oro para las tres casas de fundición existentes en el territorio: Santa María de la Antigua del Darién, Acla y Panamá. Por tratarse de la primera ciudad española fundada en la Tierra Firme (1510), la casa de la fundición de Santa María es la más antigua de la América continental. Se inaugura en 1514, poco después de la llegada del gobernador Pedrarias Dávila y, durante siete años, se realizan allí todas las labores de registro, fundición y marcación del oro en el territorio hasta entonces explorado. Sin embargo, en 1521, como resultado del desplazamiento de la población hacia la franja del Pacífico se estableció una nueva casa de fundición en Panamá. Durante varios años las fundiciones de Panamá y de Santa María de la Antigua funcionan de manera simultánea y la actividad minera se polariza en dos vertientes: por un lado, aquellos individuos que declaran en la nueva capital y, por otro, los que continúan fieles al Darién.

Desafortunadamente, como muchos enclaves fundados en el periodo inicial de asentamiento, la ciudad originaria de Santa María de la Antigua del Darién terminará siendo desmantelada. Se establecerá entonces una nueva caja en Acla para aquellos individuos que continuaron ejerciendo la minería en la costa del Atlántico. Esta dualidad Acla-Panamá se mantendrá durante algunos años más, ${ }^{14}$ aunque va perdiendo fuerza en la medida en el que el centro de gravedad del litoral atlántico se desplace a

14 Aunque se continuará fundiendo oro en Acla hasta bien entrado la década de los 40, el periodo analizado en el presente artículo termina en 1526 puesto que el territorio que nos ocupa es fundamentalmente el del Darién. Este límite temporal lo fija el desmantelamiento y desaparición de Santa María de la Antigua, cabecera de la región del Darién. 
Nombre de Dios, repoblado por orden de Pedrarias con notable éxito. Dada su importancia, la Corona dispuso en 1531 que cada año se realizase aquí una fundición general, y con este fin uno de los oficiales reales debía residir permanentemente en el citado puerto. ${ }^{15}$

Como suele suceder con los datos históricos en una fase tan temprana, la documentación analizada presenta limitaciones insalvables. Y es que, a pesar de tratarse de una fuente estandarizada con datos de periodicidad anual, en los primeros años el oro se registraba de forma anónima. De hecho, hasta 1521 un elevado porcentaje del total del oro declarado aparece a nombre de "ciertas personas". Esto lógicamente produciría distorsiones puesto que en los primeros años hay periodos en los que más del $80 \%$ del oro registrado se esconde en el anonimato. La siguiente gráfica recoge esta circunstancia. Se representa anualmente la proporción del metal declarado por grupos de personas que no se identifican en las cajas de Santa María, Acla y Panamá.

\section{GRÁFICO 1}

PROPORCIÓN DE ORO DECLARADO DE FORMA ANÓNIMA

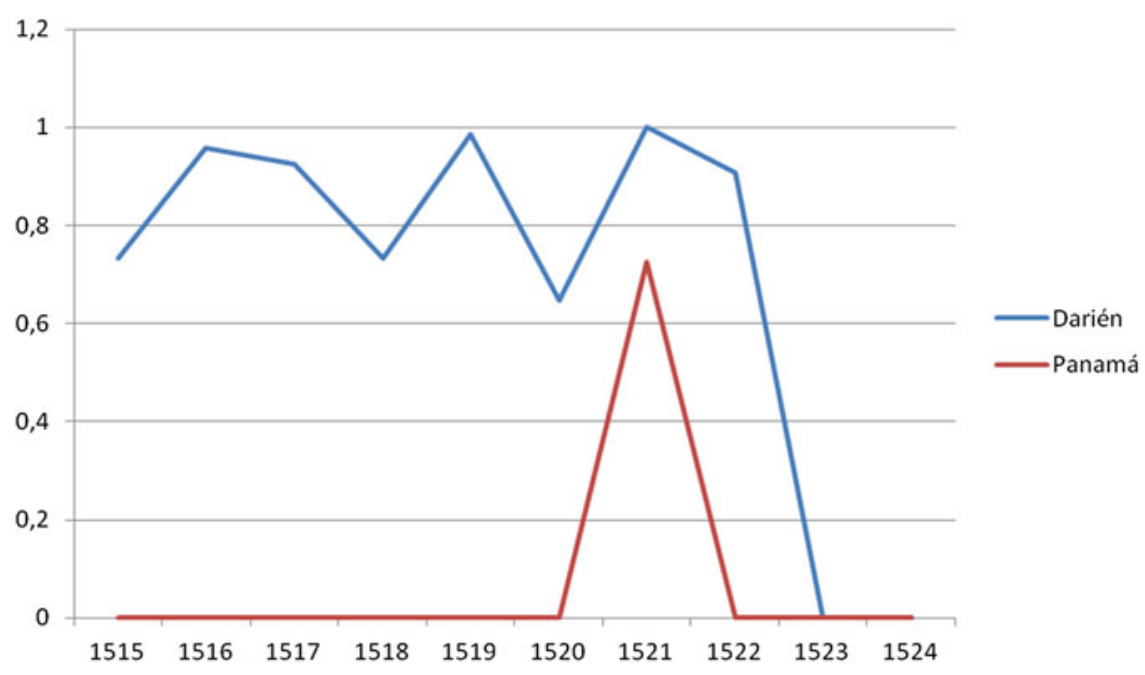

Fuente: Mena García (2011, pp. 407-426).

Véase que, por ejemplo, el año de 1521 es especialmente problemático. En la caja de Santa María de la Antigua el 100\% de los declarantes no

\footnotetext{
${ }^{15}$ Real Cédula al gobernador y oficiales de Tierra Firme. Ocaña, 4, abril, 1531. AGI, Panamá, 234,
} L.4. 
aporta datos sobre su identidad y en Panamá la proporción se acerca al $70 \%$. Este comportamiento en estos primeros años resulta lógico puesto que aún no se ha implantado un protocolo estricto a seguir en las casas de fundición. El uso del anonimato en el registro de mineral va a dificultar el control estatal y permitirá comportamientos oportunistas. Esta facilidad para la ocultación se prolongará hasta 1521, a partir de entonces en todas las declaraciones de oro debe figurar el nombre de la persona o personas responsables del registro del mineral de forma obligatoria. De hecho, esta táctica de ocultación de bienes fue castigada públicamente. Y así en el juicio de residencia del tesorero Alonso de la Puente uno de los cargos que se le imputan es precisamente el de haber consentido semejantes prácticas entre los vecinos, siendo como eran manifiestamente fraudulentas (Mena 2011a, p. 405).

En la etapa inicial comprendida entre 1514 y 1521 la táctica de la ocultación de bienes no permite utilizar los datos disponibles dado que el grueso de los registros aparece a nombre de "ciertas personas". Cualquier análisis que implique detallar nombres propios arrojaría resultados espurios puesto que los personajes más destacados registran su oro de forma anónima. Sin embargo, sí que podemos presentar indicadores básicos a modo comparativo. La siguiente tabla resume algunos valores calculados para el mismo periodo en las Casas de la Fundición del Darién, Acla y Panamá.

A simple vista la muestra analizada podría resultar modesta: 165 individuos que participan en la minería en Panamá y menos de un centenar en todo el Darién para el periodo 1522-1526, sin embargo, debe tenerse en consideración que estamos ante territorios escasamente poblados, no más de varias centenas de europeos habitan el amplio territorio.

Resulta complejo extraer la serie sobre población europea en Castilla del Oro para época tan temprana puesto que no existen recuentos pormenorizados hasta el siglo XVII. ${ }^{16}$ Los datos de los que disponemos son estimaciones y se refieren al tamaño de las diversas expediciones o aparecen dispersos en testimonios y correspondencia oficial mantenida entre funcionarios y primeros pobladores con la Corona. A la escasez de datos es necesario añadir otra circunstancia negativa y es la elevada movilidad de la población. Debe tenerse en cuenta que en ese momento el área estudiada constituía una zona de frontera con una parte importante de población de paso y en constante movimiento, atraída por la posibilidad de explorar territorios cercanos que contasen con más recursos.

16 El primer censo del que disponemos data de 1607 y se refiere al área urbana de la ciudad de Panamá. La ciudad tenía entonces una población de 5702 habitantes, véase Mena (1984, pp. 31-32). Este recuento puede consultarse en Biblioteca Nacional de España (Madrid), Mss. 3064, fols. $63 r-64 r$. 
TABLA 2

ESTADÍSTICAS DE LOS REGISTROS MINEROS (EN PESOS DE ORO)

\begin{tabular}{|l|r|c|c|}
\hline & $\begin{array}{c}\text { Santa María } \\
(\mathbf{1 5 1 4 - 1 5 2 1})\end{array}$ & $\begin{array}{c}\text { Santa María y } \\
\text { Acla 1522-1526 }\end{array}$ & $\begin{array}{c}\text { Panamá } \\
\mathbf{1 5 2 2 - 1 5 2 6}\end{array}$ \\
\hline Media & 5252,285714 & 7890,5 & 16794,33 \\
\hline Desviación Estándar & 3336,982755 & 4503,434 & 10546,5 \\
\hline Número de Registros & 32 & 120 & 201 \\
\hline Número de Personas & 34 & 88 & 165 \\
\hline
\end{tabular}

Fuente: Mena García (2011a, pp. 407-428).

Buena prueba de ello es que de los 1500 hombres llegados en la expedición de Pedrarias Dávila en 1514 quedaron reducidos a 600 en el año de 1515, tal y como se refleja en el testimonio del tesorero Alonso de la Puente. ${ }^{17}$ La elevada tasa de mortalidad europea junto con la movilidad hacia otras zonas comienza a hacer mella en la población de la región. La necesidad de mano de obra es tal que el mismo tesorero en su carta sugiere al rey la deportación al Darién de todos los condenados a muerte.

En el área del Pacífico la situación no es más favorable ya que, según el testimonio de Pascual de Andagoya en 1519, en la fundación oficial de la ciudad de Panamá están presentes tan sólo cuatrocientos europeos en total. ${ }^{18}$ Los datos sugieren que hacia 1519 no quedarían en todo el istmo más de 600 vecinos en total (Mena 2011, p. 204).

Entre los años de 1520 y 1526 nuevas expediciones llegarían a la región. Concretamente, la de Lope de Sosa que contaba con 300 hombres, y la de Pedro de Ríos de hasta 355 personas. Tan positivas noticias, sin embargo, contrastan con las constantes informaciones llegadas a la Corte sobre las dificultades de encontrar pobladores. Y es que, las expediciones hacia Nicaragua y el Perú disminuyeron considerablemente la población de Castilla del Oro que pasó a convertirse en una parada intermedia hacia territorios más alejados. Así lo demuestra la lista publicada por Mario Góngora que para los años de 1524 y 1525 contabiliza en la ciudad de Panamá tan sólo 175 vecinos, cifra que se reduciría a poco más de tres

17 El testimonio data de septiembre de 1515 y puede consultarse en Archivo General de Indias (AGI en adelante), Patronato, 26, R.5 (33). Gaspar de Espinosa escribía en el mes de diciembre y daba la misma cifra de 600 hombres. AGI, Patronato, 26, R.5 (39). Véase Mena (2011a, pp. 202203).

18 Relación de los sucesos de Pedrarias Dávila en las provincias de Tierra Firme o Castilla del Oro y de lo ocurrido en el descubrimiento del Mar del Sur y Costas del Perú y Nicaragua, AGI, Patronato, 11, véase Mena (1984, p. 45). 
decenas en los años treinta. ${ }^{19}$ Este hecho otorga a nuestra muestra un valor excepcional puesto que, para el caso de Panamá, si damos por válidas las estimaciones anteriores, el grupo de los 165 declarantes de oro que tenemos registrados en el periodo entre 1522 y 1526 constituirían más de un 94\% del total de población europea.

En cuanto a las cantidades declaradas, se observa cómo a medida que avanza el proceso de colonización el mineral registrado se incrementa. En concreto, el monto total declarado entre 1522 y 1526 aumenta en un 135\% respecto al periodo inicial. Aunque con marcadas diferencias puesto que los datos de los que disponemos apuntan a que el negocio minero resultó más lucrativo en la franja del Pacífico que en la del Atlántico.

También es cierto que los registros más tempranos presentan una mayor uniformidad puesto que las posibles desviaciones respecto del valor medio son menores. Para el caso de la caja de Panamá, la desviación estándar es de 10546,5 lo cual indica una gran variabilidad respecto a la media. En otras palabras, que mientras los registros de oro en la primera etapa de la colonización eran de menor cuantía mantuvieron una cierta regularidad mientras que en el periodo posterior la variación anual de las cantidades depositadas fue sensiblemente mayor.

En cuanto al número de declaraciones anuales, la ocultación de bienes junto con una actividad minera incipiente explica la pobreza de los datos en el periodo inicial. El desplazamiento progresivo de la mayor parte de la población hacia la franja del Pacífico incrementa la cifra de registros en la fundición de Panamá. Aunque el aumento en términos totales sea considerable, existe una cierta variación anual que es analizada en la siguiente gráfica.

Como puede comprobarse, ambas series muestran una tendencia creciente, aunque más acelerada respecto al número de individuos registrando oro. La prohibición de registrar oro de forma anónima junto con la llegada de nuevos pobladores inflará considerablemente las cifras de individuos declarando mineral en las diversas casas de fundición. En cualquier caso, los datos van a presentar una caída a partir de 1524 con la despoblación del territorio, motivada por las circunstancias ya mencionadas.

19 La lista de los 174 se inserta en un memorial dirigido a la Corona donde se reflejan los nombres de vecinos de la ciudad de Panamá que podrían participar en una pacificación, véase Góngora (1961), pp. 45 y siguientes. Teniendo en cuenta que la población de la zona era mayoritariamente masculina en edad adulta esa cifra parece bastante ajustada a la realidad, de este modo Mena García (1984, p. 48 ) y Castillero Calvo (2004) ratifican ese dato. 
GRÁFICO 2

EVOLUCIÓN REGISTROS/PERSONAS EN LA CASA DE LA FUNDICIÓN DE PANAMÁ

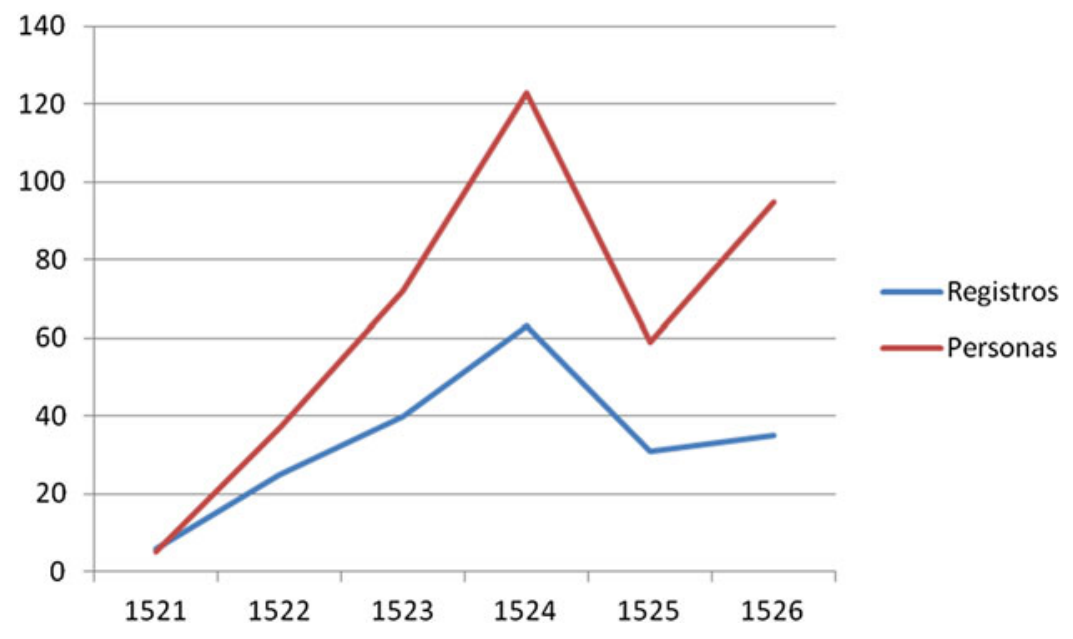

Fuente: Mena García (2011a, pp. 417-426).

\section{REDES, MOVILIDAD Y NEGOCIO MINERO EN CASTILLA DEL ORO}

Uno de los aspectos fundamentales en el análisis de redes sociales es la representación gráfica. En efecto, la elaboración de mapas es una herramienta básica a la hora de detectar patrones, estudiar comportamientos o posicionar a cada uno de los agentes dentro de una red. ${ }^{20}$ Esta propiedad es especialmente relevante cuando se trabaja con bases de datos muy extensas. Y es que, cuando la red se va ampliando y las relaciones entre agentes se solapan y se vuelven más complejas, tener una herramienta gráfica resulta imprescindible.

Para producir un grafo ha sido necesario transformar en nodos y arcos la documentación histórica generada por los funcionarios a cargo de las casas de fundición estudiadas. Cada una de las anotaciones de los libros de los oficiales reales incluye datos personales, como nombre o

${ }^{20}$ Las recientes aportaciones al análisis de redes históricas poseen un componente gráfico importante. En trabajos tales como Cachero (2011), Ribeiro (2016) o Düring (2015) se facilita la visualización de interacciones entre diversos individuos y grupos a gran escala. Esto permite captar la extraordinaria intensidad de las relaciones tanto sociales como políticas, culturales o económicas en los diversos periodos históricos. Imagen mucho más fiel a la realidad que la clásica visión estática de grupos sociales. 
profesión de los individuos que registran oro, junto con las cantidades de mineral depositadas. Estos apuntes contables representan vínculos empresariales y/o laborales en el sector minero. Las relaciones se han codificado en forma matricial asignando a cada par de individuos valor 1 si entre ellos existe una relación y 0 en caso contrario. ${ }^{21}$ Dado que el foco del análisis son las interacciones interpersonales aquellos agentes que depositaban oro de forma individual no han sido tenidos en cuenta. ${ }^{22}$

En el grafo, cada uno de los individuos estudiados representa un nodo y las líneas o arcos las relaciones entre ellos relativas al negocio minero. La naturaleza de las fuentes que usamos en este estudio nos permite reconstruir algunos de los vínculos existentes entre los pobladores del territorio, concretamente los relativos la minería. Sin embargo, en un universo tan altamente interconectado entre estos individuos existirían otros vínculos de carácter personal o familiar, pero conformarían una madeja de relaciones tan intrincadas que resultaría totalmente ineficiente para su análisis. ${ }^{23}$ La homogeneidad de los datos procedentes de las fuentes tributarias utilizados en el presente artículo nos permite representar y medir las relaciones empresariales de forma clara y precisa, sin recurrir a abstracciones o supuestos.

Al tratarse de relaciones binarias $(1,0)$ todas las líneas tienen el mismo grosor e indica si existe o no una relación entre los nodos que unen. El tamaño de cada nodo se ha ajustado según el grado, es decir, que los nodos de mayor tamaño representan individuos con mayor número de conexiones.

Las etiquetas de cada nodo expresan el nombre de la persona que representan. En este caso, y para evitar distorsiones debido al elevado número de nodos, tan sólo se han etiquetado aquellos individuos que en sus declaraciones figuraban como señores de minas. ${ }^{24}$ El color de cada nodo se refiere a la casa de fundición donde acuden a declarar. De esta forma, aquellos nodos rojos son declarantes en la región del Darién, los azules declaran siempre en Panamá mientras que los de color verde son

21 Los datos se han codificado en Excel donde cada fila y cada columna representa a un agente en el sector minero. La matriz resultante es simétrica con valores 1 y 0 señalando si existe o no relación entre cada par de agentes en la fila y columna señalada. Ignoramos la relación de cada agente consigo mismo resultando la diagonal principal de la matriz con valor cero.

22 El producto final es una matriz simétrica donde las filas o columnas de suma cero, que representan a individuos que no poseen relación con el resto, han sido eliminadas.

${ }^{23} \mathrm{La}$ naturaleza de los datos en sí -declaraciones de oro ante la Real Hacienda- limita la densidad de la red, sin embargo, ganamos en claridad y podemos detectar pautas generales de interacción dentro del grupo.

${ }^{24}$ Aunque conocemos que en este periodo histórico el negocio minero se articulaba en torno a consorcios, sólo poseemos una información muy fragmentaria al respecto. Sin embargo, en los apuntes de los oficiales reales los individuos que poseían compañía minera entre ellos distinguían ese hecho denominándose compañeros y, en ocasiones, señalando a los socios principales. 
MAPA 2

REDES MINERAS EN CASTILLA DEL ORO (1514-1526)
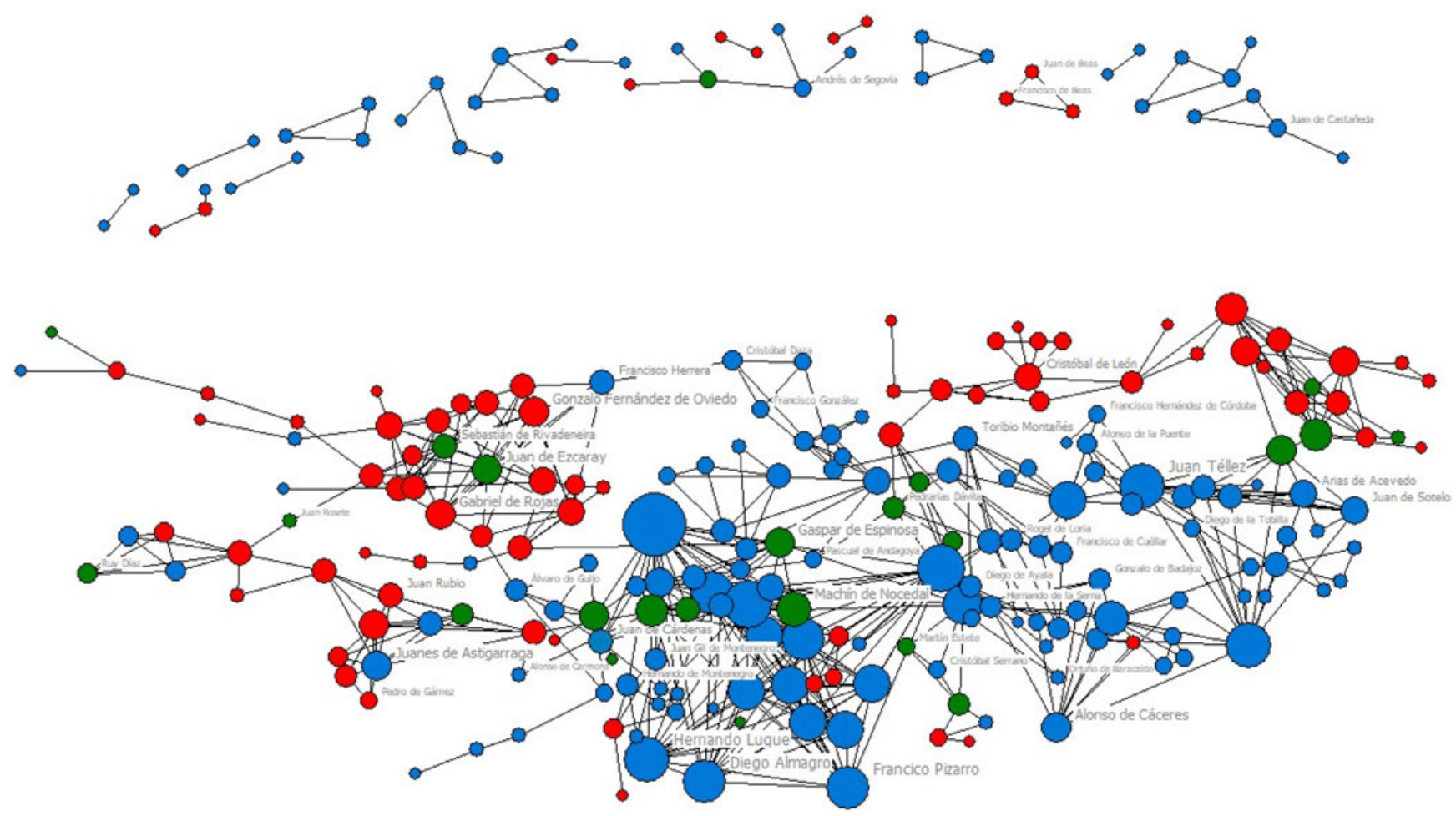
móviles, es decir, que declaran indistintamente en las dos regiones. ${ }^{25} \mathrm{Se}$ trata de captar la movilidad geográfica de la población puesto que la fuente usada nos permite conocer qué individuos permanecen establecidos en una zona en concreto y cuáles se mueven hacia otros lugares. Los resultados finales se muestran en el siguiente grafo.

Una de las principales conclusiones del análisis sobre el sector minero brasileño de Costa-Rocha-Araújo (2010) es que la movilidad a nivel geográfico constituía un factor de éxito. En el citado artículo, los autores reafirman la importancia de mantener agentes itinerantes en un contexto empresarial caracterizado por la desconfianza. En el caso brasileño la movilidad geográfica implicaba una forma de reputación puesto que tener contactos con aquellos agentes que viajaban de forma constante otorgaba un premium.

A pesar de lo atractivo del argumento, en nuestro caso esa hipótesis no se verifica. En el grafo podemos observar que los agentes que muestran movilidad geográfica, señalados en color verde, no son los que poseen más relaciones. Si bien, alguno de ellos pudieron resultar individuos exitosos en su carrera profesional, como el platero Ruy Díaz, no van a ocupar un lugar central en la red. ${ }^{26}$ En su mayoría se trata de mineros que ejercen su actividad inicialmente en el Darién pero que con el traslado de la capital hacia Panamá y el descubrimiento de oro fluvial emigran hacia el Pacífico. También los funcionarios forman parte de este grupo, puesto que con el traslado de las instituciones de gobierno los individuos al frente de las mismas deben también movilizarse. Esta circunstancia explica que sean los agentes que declaren en Panamá los que se encuentren mejor conectados.

Es el caso de Castilla del Oro particular a este respecto puesto que la movilidad geográfica responde a decisiones políticas y no a cuestiones económicas. Y es que desde el mismo momento de la fundación de Panamá (1519), el objetivo perseguido por el gobernador Pedrarias Dávila consistió en atraer a la nueva capital del territorio el máximo número de colonos. La política de atracción utilizada fue la del reparto de encomiendas entre los nuevos vecinos. En efecto, son muchos los individuos que por primera vez aparecen registrando oro en Panamá bajo el título de encomendero. Esta facilidad en el acceso a grandes extensiones

25 Es necesario recordar que la región del Darién agrupa las casas de fundición de Santa María de la Antigua y de Acla, la primera activa desde 1514 hasta 1523 y la segunda a partir de 1524 .

${ }^{26}$ Este controvertido personaje que viajó como soldado en el ejército de Pedrarias Dávila, compatibilizó su actividad como fundidor y aquilatador de piedras preciosas con el consorcio que compartió con Juan Zamora de Alconchel con un capital social de casi 4.000 pesos. En el año de 1524 registraba Ruy Díaz 29 pesos en Acla junto con su minero Martín de Montemayor y 634 pesos de forma individual en Panamá. Su posición de funcionario al servicio de la Corona le obligó a trasladarse a la nueva capital junto al gobernador. Allí continuó simultaneando su cargo con el negocio minero, pero sin abandonar sus intereses en la costa atlántica. De hecho, el negocio en Acla no dejó de dar sus frutos y en 1525 declaraba ante Caja Real la nada despreciable suma de 1452 pesos. Mena García (2011a, pp. 396-398). 
de tierra y, sobre todo, a indios tributarios convirtió a Panamá en una competidora desleal y propició el despoblamiento progresivo de Santa María de la Antigua.

En cualquier caso, si la geografía no resulta un elemento clave para entender el éxito en el sector minero ¿cuáles serían las variables que lo explican? En otras palabras ¿quiénes son los individuos centrales y por qué? Para dar respuesta a estos interrogantes es necesario explorar las medidas generales y específicas de la red anteriormente representada.

\subsection{La clave del éxito}

La red cuenta con un total de 253 agentes que comparten más de 600 conexiones. El grafo recoge la información de los oficiales reales sobre las relaciones en el sector de la minería. Obviamente lo que representamos es tan sólo una parte de la interacción real entre estos individuos que, por razones políticas, militares o sociales se encuentran altamente interconectados. La siguiente tabla agrupa las principales medidas de red.

TABLA 3

MEDIDAS GENERALES DE RED

\begin{tabular}{|l|c|l|r|}
\hline Medida & Valor & \multicolumn{1}{c|}{ Medida } & \multicolumn{1}{c|}{ Valor } \\
\hline Nodos & 253 & Grado Medio & 4,49 \\
\hline Arcos & 662 & Índice de centralización & $18,49 \%$ \\
\hline Distancia Media & 5,789 & Intermediación & 396,941 \\
\hline Diámetro & 15 & Clustering & 0,689 \\
\hline Densidad & 0,018 & Fragmentación & 0,342 \\
\hline
\end{tabular}

Fuente: Datos de UCINET 6.

Podemos observar que se trata de una red compleja que cuenta con un número considerable de agentes, aunque con una densidad baja. El término densidad está relacionado con la conectividad en términos generales del grupo analizado y es un concepto genérico que se calcula para la red en conjunto, es decir, desde fuera lo que medimos es si la red es muy tupida o no. ${ }^{27} \mathrm{Si}$ en lugar de calcular una medida externa quisiéramos saber si los individuos dentro de la red están muy bien conectados o no,

27 La densidad se calcula como Número de Conexiones Reales/ Número de Conexiones Posibles y sus valores oscilan entre 0 y 1 . Una red con densidad igual a 1 indica que la conectividad es del $100 \%$, es decir, que todos los agentes están conectados entre sí. 
acudiríamos a la centralidad. El concepto de centralidad nos permite saber cómo son las conexiones a nivel interno en la red, o sea, en qué grado los agentes actúan de forma conjunta o si lo hacen de forma individual. Se han calculado tres indicadores de centralidad distintos: el grado medio, el índice de centralidad y la intermediación. La primera de las medidas nos indica que en la red los individuos, por término medio, comparten 4,49 conexiones. A modo comparativo, podemos señalar que en las redes calculadas por Costa-Rocha-Araújo (2010) el grado medio se situaba entre 2,3 y 2,5. En cuanto al índice de centralidad, tan sólo mide en porcentajes la cercanía entre nuestro grafo y uno en forma de estrella que comprende un único agente central y el resto orbitando alrededor, es precisamente este agente central el encargado de conectar a todos. ${ }^{28} \mathrm{El}$ valor del grado de centralización indica que la cercanía entre un grafo en forma de estrella y nuestro caso es tan sólo del 18,49\% lo cual indica que aún estamos bastante alejados de este modelo donde un solo agente controla toda la información. Podemos afirmar que, en nuestro caso, por tanto, existe un número elevado de actores intermedios en la red con capacidad de acceso a la información que circula por la misma. Esto mismo parece indicar el valor de la intermediación, y es que por término medio son 396,941 veces las que un actor está en la mitad de camino entre un par de nodos. Estos dos últimos parámetros indican claramente la presencia de actores intermedios que conectan a su vez a otros agentes en la red.

En definitiva, estamos ante una red amplia, que cuenta con un número de sub-grupos altamente conectados entre sí por una serie de individuos que resultan claves. No es de extrañar, por tanto, que el coeficiente de clustering sea elevado $(0,689)$ haciendo referencia al hecho de que es posible dividir la red en una serie de grupos. Sin embargo, al mismo tiempo, la fragmentación es baja, en torno al 34\%, indicando el porcentaje de pares de nodos que no se pueden alcanzar entre ellos es relativamente pequeño. En otras palabras, que nuestra red es resultado de un número de pequeños cores con individuos que comienzan a moverse de un grupo a otro generando un número más elevado de conexiones.

Esta imagen está muy alejada del ideal de empresa en el Viejo Mundo donde la pertenencia a un grupo constituye en sí mismo un elemento de control, de este modo, los individuos tienen acceso a las transacciones inter grupo y aquellos que muestran comportamientos oportunistas o desleales son castigados con la exclusión de todos los negocios futuros. Esta es precisamente la hipótesis que subyace en el análisis sobre los comerciantes magrebíes de Avner Greif (1993; 1989), idea que es

${ }^{28} \mathrm{El}$ grafo en forma de estrella es aquel que cuenta con un nodo central conectado a todos los demás y que controla toda la posible información de la red, mientras más alejados estemos de este modelo más agentes tendremos en medio del camino con posibilidades de acceso a la información que circula por el grafo. Para más información véase Wasserman y Faust (2012, capítulo 5). 
fácilmente extrapolable a los consulados y otras instituciones comerciales en Europa pero que, sin embargo, no parece aplicable a nuestro caso. ${ }^{29}$ No debemos olvidar que esta es una sociedad de frontera, con una geografía hostil, donde las alianzas son efímeras y donde prevalece el individuo al grupo. Al igual que en Costa-Rocha-Araújo (2010) la movilidad es una variable clave para explicar el éxito en el sector minero, pero, en nuestro caso, no tiene asociada necesariamente un componente geográfico, sino que se trata de una rotación de carácter laboral. Es decir, que los individuos más relevantes en el sector son aquellos que se mueven de un consorcio minero a otro y se encargan de conectarlos. La cuestión clave sería conocer quiénes son estos individuos y explicar el porqué de esta movilidad. Con este fin, se ha confeccionado la siguiente tabla que presenta en forma de rankings las listas de individuos mejor conectados en la red.

TABLA 4

RANKINGS EN BASE A INDICADORES DE CENTRALIDAD

\begin{tabular}{|l|l|l|}
\hline Grado & \multicolumn{1}{|c|}{ Intermediación } & \multicolumn{1}{c|}{ Relevancia } \\
\hline Alonso de Carvajal & Alonso de Carvajal & Juan Montesdoca \\
\hline Juan Montesdoca & Alonso López & Diego de Cuevas \\
\hline Diego de Cuevas & Gaspar de Espinosa & Hernando Luque \\
\hline Hernando Luque & Diego del Corral & Francisco Pizarro \\
\hline Juan Téllez & Hernando de Zaera & Diego Almagro \\
\hline Juan Méndez & Alonso Rodríguez & Pedro Alonso Calvo \\
\hline Francisco Pizarro & Diego de Cuevas & Juan Morantes \\
\hline Diego Almagro & Toribio Montañés & Alonso de las Roelas \\
\hline Pedro Alonso Calvo & Francisco Ortega & Simón del Campo \\
\hline Juan Morantes & Juan Méndez & Pedro López \\
\hline
\end{tabular}

Fuente: Datos de UCINET 6.

Se han organizado los datos en torno a tres indicadores: grado, intermediación y relevancia. Grado e intermediación ya se han calculado con anterioridad en relación con la red general mientras que, relevancia, es un concepto nuevo que indica quiénes son los actores más influyentes

29 Véase Avner Greif (2006). Sobre consulados véase Smith (1972), Grafe (2012), Basas Fernández (1985) y Heredia Herrera (1983). Entre otras instituciones mercantiles es de destacar la aportación de Hancock (1997), González de Lara (2002), Boerner y Quint (2010). 
según las personas a las que están conectados. ${ }^{30}$ Es decir, que un agente es relevante no sólo por el número de conexiones que tenga (grado), ni por el número de personas a las que él mismo conecte a la red (intermediación) sino si sus amigos son importantes o no (relevancia).

De los individuos que aparecen en la tabla anterior, un 60\% declaran ser mineros de profesión, el 30\% son encomenderos y el 10\% ocupan puestos en la administración local. Es evidente que los mineros profesionales ocupaban un lugar privilegiado en la red. Y es que, aunque las cuadrillas de trabajo para el bateo del oro en el río estaban integradas por indígenas, el capataz a cargo de ellos solía ser europeo y necesitaba tener algún conocimiento de las técnicas para el beneficio y lavado del oro. Obviamente, la concentración de las relaciones en torno a estos agentes es sinónimo de la escasez de capital humano y es esta circunstancia la que los convierte en protagonistas absolutos. Tal y como Costa-Rocha-Araújo (2010) afirman para el oro brasileño "such a concentration of relations indicates a scarcity of individuals with appropiate attributes", (Costa-Rocha-Araújo 2010, p. 20). Además, no debemos olvidar que es el minero trabajando para diversos señores de minas el que posee información de primera mano acerca de la marcha del negocio, y de este modo, va formándose toda una red de contactos que explica la elevada rotación de las cuadrillas de profesionales.

La categoría "encomendero" muchas veces esconde a capitanes y religiosos. En la tabla encontramos, por ejemplo, la famosa triada de los futuros socios para la conquista del Perú -Francisco Pizarro, Diego de Almagro y el padre Hernando Luque- junto con personalidades menos conocidas pero relevantes como Hernando Zaera -escudero y hombre de confianza de Pedrarias Dávila- y el capitán Juan Téllez que participó en las expediciones hacia Nicaragua en compañía del gobernador segoviano (Mena García 2011, pp. 437 y siguientes). También entre los funcionarios locales que figuran en la tabla algunos participaron en acciones de conquista. El bachiller Gaspar de Espinosa, por ejemplo, llegó al Darién con la armada de Pedrarias Dávila como alcalde mayor de Castilla del Oro y participó en numerosas expediciones de conquista. ${ }^{31}$

De todos los nombres anteriores, uno en concreto se repite en los tres rankings. ${ }^{32}$ Se trata del minero Diego de Cuevas que trabajó para el

${ }^{30}$ La relevancia es una medida de centralidad y puede interpretarse como la capacidad de un individuo para influenciar en la red, esa capacidad se la otorga el hecho de estar directamente vinculado con los agentes más importantes. La relevancia se calcula mediante los valores del Eigenvector, su uso para el Análisis de Redes Sociales fue introducido por Bonacich (1972).

31 Sobre este personaje véase Información de méritos y servicios de Gaspar de Espinosa y de su hijo Juan de Espinosa, en Lima, 26, febrero, 1552. AGI, Patronato 98 A, N.2, R.1.

32 Debido a su escasa relevancia a nivel político de los mineros que mencionamos casi no poseemos datos biográficos, no obstante, algunos de los casos que presentamos han sido estudiados en Mena García (2011) y (1984). 
consorcio Pizarro-Almagro-Luque entre 1524 y 1525 y tan sólo un año más tarde para la acaudalada compañía formada por Hernando de Zaera y el encomendero Juan Panés. El también minero Juan Montesdoca encabeza el ranking de relevancia. Montesdoca prestó sus servicios en 1523 en la compañía de Juan de Cárdenas y un año más tarde se integró en el consorcio de los futuros conquistadores del Perú. Esta última circunstancia no impidió que Juan de Montesdoca se independizara comenzando a fundir oro en exclusividad. El más solicitado de los mineros fue, sin embargo, Juan Méndez. De hecho, entre los años de 1522 a 1526 trabajó al servicio de cuatro consorcios mineros distintos. A pesar de presentarse como minero de la compañía integrada por los encomenderos Arias de Acevedo y Juan Téllez, a su servicio desde 1522 a 1526, lo encontramos fundiendo oro en 1523 en comandita con Diego de la Tobilla, el famoso compañero de Balboa en el descubrimiento de la Mar del Sur. ${ }^{33}$ En 1524 Juan Méndez se encuentra asociado al contador Alonso de Cáceres, mientras que en 1525 funde oro con Jerónimo Sánchez y el encomendero Diego de la Vega.

En los casos anteriormente señalados, son los mineros los que conectan las diversas comunidades en la red. En términos de la teoría de Mark Granovetter (1973) podemos afirmar que los individuos que mantienen relaciones personales o económicas intensas, los llamados lazos fuertes, suelen ser parte de grupos, más o menos estables en su composición, pero que tienen tendencia a separarse del resto de la red en el largo plazo. Mientras que, en el otro extremo, tenemos relaciones esporádicas o causales donde el nexo de unión no es definitivo: son los denominados lazos débiles. La importancia de los lazos débiles radica en su flexibilidad y en la capacidad de actuar como puente uniendo entre sí grupos que son más sólidos y, por tanto, están aislados de los demás.

\subsection{La fidelidad o los conjuntos autónomos}

En un escenario laboral tan promiscuo como el planteado, llama la atención aquellos grupos de composición estable. Es decir, aquellos en los que los miembros se prestan fidelidad y acuden a fundir oro siempre de forma conjunta. Este tipo de grupos que matemáticamente se denominan conjuntos autónomos aparecen en el grafo como triángulos o polígonos independientes de los demás (Mowshowitz y Dehmer 2012). El siguiente mapa muestra una sección del grafo anterior donde se

33 Diego de la Tobilla escribió La Barbárica una obra dedicada a criticar las acciones de Pedrarias Dávila en Castilla del Oro. Véase Suárez Fernández y Lucena Salmoral (1982), Mena García (1984). 
aprecian con mayor claridad los grupos a los que nos referimos, el color de nuevo representa la ubicación de la casa de fundición donde declaran oro.

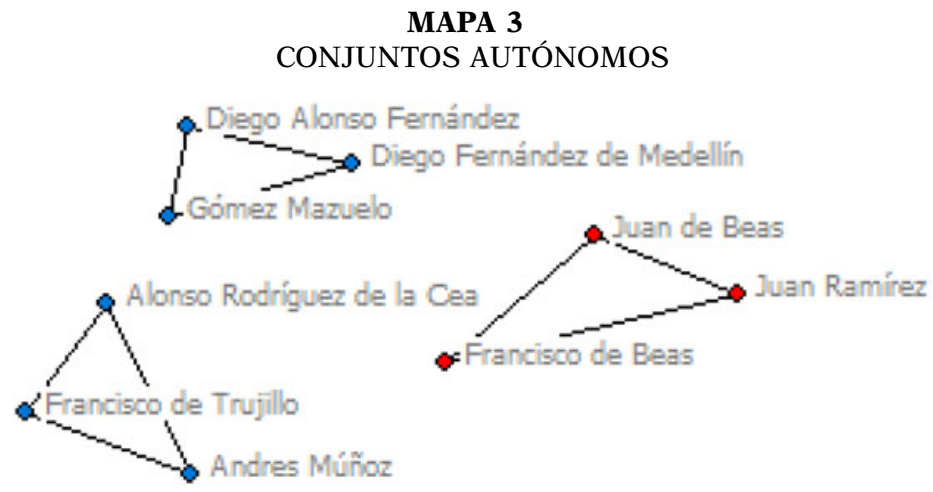

Fuente: Datos de UCINET 6.

De los tres grupos autónomos que detectamos en el grafo tan sólo uno de ellos pertenece a la zona del Darién. En efecto, el consorcio minero integrado por los hermanos Juan y Francisco de Beas junto con el minero Juan Ramírez funde oro en dos ocasiones en Santa María de la Antigua y, una vez desmantelada la ciudad, se trasladan a Acla para fundir el mineral. Sabemos que el monto total de sus declaraciones es bastante modesto, pues fundieron 1.306 pesos de oro, cantidad bastante menor que los 16.195 pesos registrados por los mineros de Pedrarias Dávila durante los mismos años.

De los vecinos panameños no poseemos demasiada información. El encomendero Diego Fernández de Medellín aparece asociado a Diego Alonso Fernández, del que ni siquiera conocemos su profesión, y al minero Gómez Mazuelo. Estructura similar posee el último de los consorcios, el de los encomenderos Francisco de Trujillo y Andrés Muñoz junto con el minero Alonso Rodríguez de la Cea.

Al tratarse de grupos reducidos en cuanto al número de miembros y declarando cantidades inferiores al resto, no poseemos datos suficientes para realizar un análisis en profundidad. Además, estos individuos estaban escasamente conectados y no tuvieron un papel relevante en la vida política de Castilla del Oro por lo que desafortunadamente no podemos ofrecer ni siquiera un perfil aproximado de estos agentes. ${ }^{34}$

$34 \mathrm{Al}$ igual que ocurre con los mineros profesionales la única información que tenemos sobre estos actores proviene de las fuentes originales que, en parte, han sido analizadas en Mena García (2011a). 


\section{EL CONCEPTO DE LIDERAZGO Y OTRAS DINÁMICAS DE GRUPO}

Si bien es sabido que un reducido grupo de individuos permanecen al margen, la inmensa mayoría de los españoles que poblaban estos territorios desplegaron todo tipo de estrategias de promoción, social y laboral, a muy corto plazo. Como se ha explicado con anterioridad, las alianzas entre los poderes políticos y económicos mutaban constantemente y las traiciones y nuevos pactos estaban a la orden del día. En este escenario tan incierto, resulta extremadamente complejo estudiar la población en forma de comunidades o grupos puesto que las acciones y decisiones solían tener un componente individualista. Sin embargo, a pesar de las dificultades señaladas, el análisis de redes nos permite aislar algunas dinámicas de grupo y modelos de liderazgo que merece la pena analizar.

A título comparativo es necesario examinar las diferencias en términos de liderazgo de las figuras que mayor relevancia tendrán a nivel histórico. Nos referimos al gobernador Pedrarias Dávila, a Vasco Núñez de Balboa ${ }^{35}$ y al grupo de los tres socios de la empresa de Levante futuros conquistadores del Perú (Francisco Pizarro, Diego de Almagro y el padre Hernando Luque). Es cierto que tanto Balboa como Pedrarias se mostraron interesados en la minería del oro, pero su actuación fue bien distinta. Analizando la información disponible y el modus operandi de cada uno de ellos se observan dos modelos de liderazgo distintos. Pedrarias Dávila no suele registrar oro personalmente, sino que generalmente son los mineros a su servicio los que declaran en su lugar. Y es que las constantes expediciones capitaneadas por el gobernador y las obligaciones políticas que conllevaba su cargo le obligarían a depositar sus intereses en el sector minero en manos de hombres de confianza y trabajadores leales, como su escudero Hernando de Zaera y los mineros Francisco Romero, Gonzalo Ruiz o Gregorio Ponce. Se trata de una estrategia de delegación del poder que tendrá como consecuencia la creación de vínculos más sólidos y permanentes. De hecho, estamos ante una de las cuadrillas más estables a pesar de que en 1525 Hernando de Zaera simultaneará el trabajo a las órdenes de Pedrarias con su propia empresa. Los mineros mencionados permanecieron fieles al gobernador, aunque el consorcio en años puntuales precisó de los servicios de otros profesionales con carácter eventual. ${ }^{36}$

${ }^{35}$ Para referirnos a Balboa usamos el término caudillo puesto que no llegó a ostentar oficialmente el título de gobernador. En una Real Cédula de 31 de diciembre de 1511 el rey le concedió el cargo de gobernador interino del Darién "entretanto que mandamos proveer de gobernador y justicia de la provincia del Darién que es en Tierra Firme”, AGI, Indiferente General, 418, L 3. Algo más tarde y tras su descubrimiento de la costa del Pacífico la corona no tuvo más remedio que concederle el título casi honorífico de Adelantado de la Mar del Sur y gobernador de Panamá y Coiba. Véase Mena García (2011a, pp. 177 y 190).

${ }^{36}$ En concreto nos referimos al espacio de tiempo en el que el conocido minero Alonso López que prestó sus servicios al consorcio creado por Pedrarias Dávila. 
Diferente a este modelo de liderazgo es la actividad desplegada por el caudillo Vasco Núñez de Balboa, autoridad política en la colonia hasta la llegada del gobernador Pedrarias. En el periodo inicial, entre 1514 y 1520, Balboa será el protagonista central de la red minera al presentar en primera persona los registros del oro ante los oficiales reales. Estamos, por tanto, ante modelos de liderazgo diferentes: mientras que Balboa se muestra personalista y actúa en nombre propio, Pedrarias lo hace por medio de intermediarios.

Si bien en una forma o en otra los anteriores personajes ejercen de líderes no ocurre así con Francisco Pizarro quien, al menos en esta etapa de Castilla del Oro, actúa de forma coordinada con sus compañeros Almagro y Luque. La sociedad minera formada por el futuro conquistador del Inca y sus socios tributa generalmente de forma conjunta y da trabajo a un número considerable de mineros, hasta diez son registrados en nómina de la compañía, aunque no presten sus servicios de forma exclusiva. ${ }^{37}$ Los capitanes Pizarro y Almagro compañeros inseparables en diversas expediciones tardaron bastante en incorporarse al negocio minero. No es hasta 1522 que declaran oro por primera vez ante los oficiales reales de Panamá, a pesar de haberse constituido oficialmente en compañía minera desde 1521(Mena García 2011a, pp. 417 y siguientes). En concreto registraron ese año 2.055 pesos de oro, equivalentes a un 18,5\% del total de la recaudación anual en la Caja Real. Tan sólo un año más tarde, aparecen ambos capitanes junto con su compañero el padre Hernando Luque, a partir de entonces tributarán siempre de forma conjunta con la salvedad de que los nombres de los mineros van alternándose. En el siguiente mapa se muestran las conexiones del clúster en torno a los tres conquistadores. ${ }^{38}$

De todos los miembros de la red tan sólo uno de ellos, Francisco Ortega, aparece en los registros del Darién y de Panamá. En concreto, Ortega declara en Acla, en 1526, una partida de mineral junto con el encomendero Martín Martínez y también registra oro de forma independiente. Aparte de los tres conquistadores y sus mineros, en el grafo figura también el minero Francisco Pesado que, sin tener relación directa con la compañía, declara mineral en una ocasión junto con el padre Hernando Luque.

El legendario vínculo que se fraguó entre Pizarro y Almagro en Panamá es sin duda uno de los más estables y duraderos en esta etapa. ${ }^{39}$ En su

\footnotetext{
${ }^{37}$ Los mineros que estuvieron vinculados al consorcio de los conquistadores del Perú fueron Simón del Campo, Alonso de las Roelas, Pedro López, Francisco de Trigueros, Juan Morante, Juan Montesdoca, Francisco Ortega, Diego de Cuevas, Pedro Alonso Calvo, Alonso de Carvajal y Jerónimo del Campo. Mena (2011a, p. 443).

${ }^{38}$ Al igual que en el resto de grafos, los nodos han sido redimensionados según el grado y el color representa el lugar donde declaran oro.

${ }^{39}$ Pizarro llegaría a Tierra Firme en 1510 con la armada de Ojeda para la conquista del golfo de Urabá mientras que Almagro y el padre Hernando Luque lo harían junto con el
} 
MAPA 4

LA COMPAÑÍA PIZARRO-ALMAGRO-LUQUE

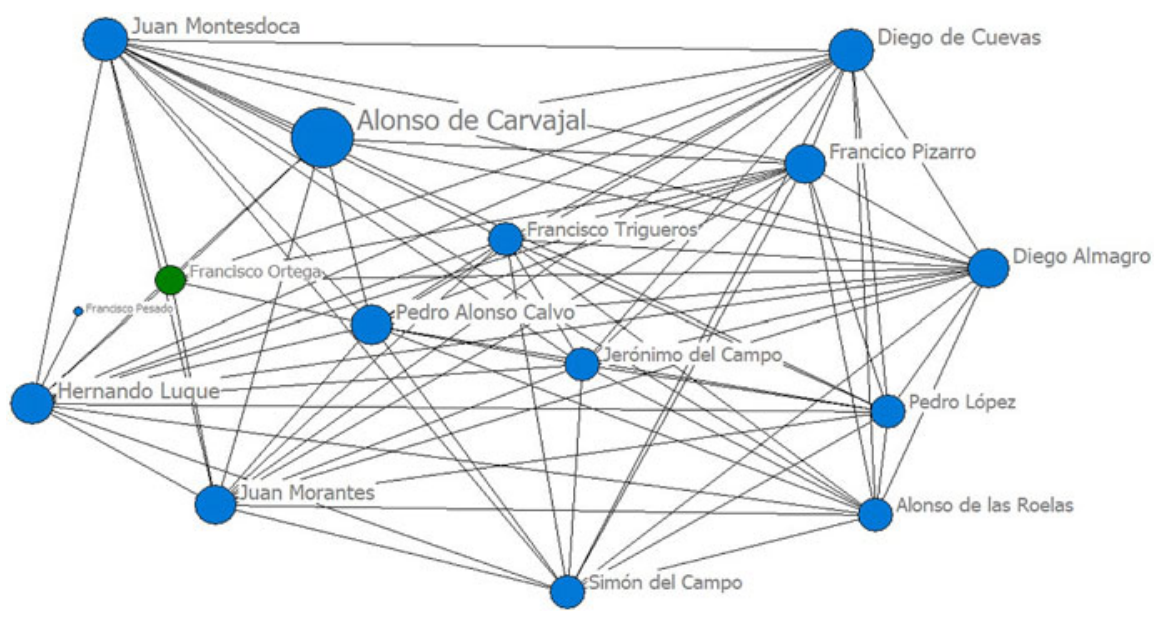

Fuente: Véase el texto.

crónica Fernández de Oviedo así lo certifica cuando afirma que "E fueron ambos - dice Oviedo - tan buenos compañeros e tan avenidos y en tanta amistad e conformidad que ninguna cosa de hacienda, ni indios, ni esclavos, ni minas en que sacaban oro con su gente, ni ganados había entre ellos sino común e no más del uno que del otro, mucho mejor que hermanos" (Fernández de Oviedo 1959, Vol II, p. 97). La aparente solidez de la relación entre los conquistadores durante la etapa panameña se quiebra en el escenario peruano donde las traiciones y la enemistad entre ellos se salda con la ejecución de Diego de Almagro por orden de Pizarro en 1538. Este comportamiento viene a confirmar nuestra hipótesis sobre la inestabilidad de los vínculos entre los colonos de las primeras ciudades en la América continental.

\section{CONCLUSIONES}

La gobernación de Castilla del Oro es ciertamente un territorio al que pocos historiadores han prestado atención. No obstante, posee una relevancia extraordinaria por tratarse del primer asiento europeo en la América continental. Estos primeros ensayos colonizadores constituirán

gobernador Pedrarias Dávila en 1514. Véase Busto Duthurburu (2001), Lavallé (2004) y Mena (2015). 
un precedente para el resto. De hecho, el método aplicado por la monarquía de los Habsburgo en América, que tendrá su germen en el Caribe, se basaba precisamente en la prueba y error. Vemos en estos experimentos iniciales fallos y rectificaciones que se incorporarán a la legislación y servirán de precedente para territorios más amplios y relevantes como México o Perú.

La zona analizada posee además elementos característicos de sociedades de frontera con condiciones de vida extremas. La exploración del territorio adyacente junto con la búsqueda de recursos constituyen factores de atracción de una población increíblemente dinámica donde los mecanismos de lealtad-deslealtad son efímeros y las relaciones de confianza-desconfianza cambiantes. Es esta nueva sociedad colonial un territorio hostil, con relaciones económicas y políticas casi predatorias, y completamente alejado de las normas e instituciones imperantes en el Viejo Mundo.

El presente artículo enriquece, sin duda, el campo de las Humanidades Digitales. Los minuciosos registros históricos analizados permiten no sólo corroborar la existencia de relaciones entre diversos agentes económicos, sino medir su fortaleza de forma clara y objetiva. La visualización mediante grafos ayuda a detectar patrones de comportamiento, estudiar diversos modelos de liderazgo o mostrar dinámicas de grupo. Por su parte, el análisis de redes complementario nos muestra aspectos más concretos, como el papel jugado por los profesionales de la minería como conectores en las diversas redes.

Finalmente, aspectos tales como la elevada rotación laboral o las estrategias de ascenso laboral han sido abordados en este artículo. Aunque se han mencionado algunas de las causas que explican este fenómeno aún desconocemos los medios usados, las motivaciones en cada caso y, sobre todo, la rentabilidad de estos comportamientos. Éstas son cuestiones que se abordarán en un artículo complementario.

\title{
AGRADECIMIENTOS
}

Received 1 December 2017. Accepted 8 January 2019

Nos gustaría agradecer a los tres referees anónimos por las sugerencias e ideas para mejorar el manuscrito. Asumimos la responsabilidad por cualquier error u omisión.

\section{FUENTES Y PUBLICACIONES OFICIALES}

\author{
ARCHIVO GENERAL DE INDIAS (AGI), Secciones Patronato y \\ Panamá.
}


COLECCIÓN MUÑOZ, Catálogo de documentos interesantes para la Historia de América, Editado por la Real Academia de Historia, Madrid, Vols. I, II y III.

\section{BIBLIOGRAFÍA}

Alzate Gallego, A. (2011): "Santa María de la Antigua del Darién: un enclave español en el Darién colombiano del siglo XVI", Estrat Crític 5. Vol. 1 (2011): 352-358.

Anglería, P. (1989): Décadas del Nuevo Mundo. Introducción de Manuel Alba. Madrid.

ARAm, B. (2008): Leyenda negra y leyendas doradas en la conquista de América. Pedrarias y Balboa. Madrid: Marcial Pons, Ambos Mundos.

Basas Fernández, M. (1985): "La función del Consulado de Burgos en el apogeo económico de Castilla", La Ciudad de Burgos. Actas del Congreso de Historia de Burgos, Burgos, pp. 233-246.

Becerra, V. y Vignolo, P. (2011): Tierra Firme. El Darién en el imaginario de los conquistadores, Bogotá: Universidad Nacional de Colombia e INAH.

Bonacich, P. (1972): “Technique for Analyzing Overlapping Memberships", Sociological Methodology, Vol. 4, pp. 176-185.

Boerner, L. y Quint, D. (2010): “Medieval Matching Markets”, SSRN Working Paper Series https://papers.ssrn.com/sol3/papers.cfm?abstract_id=1727700

Busto Duthurburu, J. A. (2001): Pizarro, Lima.

Cachero Vinuesa, M. (2011): "Redes mercantiles en los inicios del comercio atlántico. Sevilla entre Europa y América, 1521-1525" en B. Hausberger, A. Ibarra y $\mathrm{N}$. Böttcher (eds.), Redes y negocios globales en el mundo ibérico, siglos XVI-XVIII, México: El Colegio de México, pp. 25-52.

CASAS, B. (1957): Historia de las Indias. Madrid, B.A.E., 1957 (estudio y notas de J. Pérez de Tudela).

Castillero Calvo, A. (2004): Historia General de Panamá, 5 vol., Panamá: Comité Nacional del Centenario de la República.

Chaunu, P. et Chaunu, H. (1955-1959) : Seville et L'Atlantique, 1504-1650. 11 vols., París.

Costa, L. F., Rocha, M. M. y AraúJo, T. (2010): "Social Capital and Economic Performance: Trust and Distrust in Eighteenth-Century Gold Shipments from Brazil", European Review of Economic History, Vol. 15, pp. 1-27.

Crovi Druetta, D. M., López Cruz, M. A. y López González, R. (2009): Redes sociales: Análisis y aplicaciones, México D. F.: Universidad Autónoma de México y Plaza y Valdés.

Düring, M. (2015): Verdeckte soziale Netzwerke im Nationalsozialismus Die Entstehung und Arbeitsweise von Berliner Hilfsnetzwerken für verfolgte Juden. Hidden Social Networks in National Socialism: The origins and working methods of Berlin assistance networks for persecuted Jews, Berlin: De Gruyter.

Freeman, L. (2004): The Development of Social Network Analysis: A Study in the Sociology of Science, Vancouver: Empirical Press.

Fernández De Oviedo, G. (1959): Historia general y natural de las Indias, 5 Volúmenes, Madrid: Ediciones Juan Pérez de Tudela.

García Casares, J. (2008): Historia del Darién. Cuevas, cunas, españoles, afros, presencia y actualidad de los chocoes. Panamá: Editorial Universitaria Carlos Manuel Gasteazoro.

Góngora, M. (1961): Los grupos de conquistadores en Tierra Firme (1509-1530): Fisonomía histórico-social de un tipo de conquista, Santiago de Chile. 
GonZÁlez De LaRA, Y. (2002): "Institutions for Contract Enforcement and Risk Sharing: From the Sea Loan to the Commenda in Late Medieval Venice", European Review of Economic History, Vol. 6, pp. 257-262.

Grafe, R. (2012): Distant Tyranny. Market, Power and Backwardness in Spain, 1650-1800, Princeton: Princeton University Press.

Granovetter, M. (1973): "The Strength of Weak Ties", The American Journal of Sociology, 78, pp. 1360-1380.

GreIF, A. (2006): Institutions and the Path to the Modern Economy: Lessons from Medieval Trade. Cambridge University Press

GreIF, A. (1993): "Contract Enforceability and Economic Institutions in Early Trade: The Maghribi Traders' Coalition", The American Economic Review, Vol. 83, N. 3, pp. 525-548.

GreIF, A. (1989): "Reputation and Coalitions in Medieval Trade: Evidence on the Maghribi Traders", The Journal of Economic History, Vol. 49, N. 4, pp. 857-882.

Hancock, D. (1997): Citizens of the World: London Merchants and the Integration of the British Atlantic Community. New York: Cambridge University Press.

HARING, C. H. (1979): Comercio y navegación entre España y las Indias en la época de los Habsburgo. Primera edición en inglés, 1918, segunda edición española, México: Fondo de Cultura Económica.

Heredia Herrera, A. (1983): "Historia de un depósito documental: El Archivo del Consulado de Cargadores de Sevilla", Andalucía y América en el siglo XVI. Actas de las Segundas Jornadas de Andalucía y América, Vol. I, pp. 485-499.

Lavallé, B. (2004): Francisco Pizarro. Conquistador de l'extrème. París: Payot y Riages. La versión española: Francisco Pizarro. Biografía de una conquista. Traducción de Sandra Recarte. Lima: IFEA, IEP.

Lohmann Villena, G. (1968): Les Espinosa: Une familla d'hommes d'affaires en Espagne et aux Indes à l'époque de la colonisation. París: Ecole Pratique des Hautes Etudes en Sciences Sociales.

Lucena Salmoral, M. y Suárez Fernández, L. (1982): El descubrimiento y la fundación de los reinos ultramarinos: Hasta fines del siglo XVI, Barcelona: Ediciones Rialp.

Mena García, C. (2015): "Santa María de la Antigua del Darién: la huella de una ciudad perdida”, en J. Buxeda, M. Madrid y J. G. Ibáñez, (eds.) Global Pottery 1. Historical Archaeology and Archaeocometry for Societies in Contact. Oxford: Bar International Series, pp. 253-263

Mena García, C. (2011a): El oro del Darién. Entradas y cabalgadas en la conquista de Tierra Firme, Sevilla: Centro de Estudios Andaluces (CENTRA) y CSIC.

Mena García, C. (2011b): "La frontera del hambre: construyendo el espacio histórico en el Darién", en P. Vignolo y V. Becerra (eds.) Tierra Firme. El Darién en el imaginario de los conquistadores. Bogotá: Universidad Nacional de Colombia e Instituto Colombiano de Antropología e Historia, pp. 215-255.

Mena García, C. (1992): La ciudad en un cruce de caminos (Panamá y sus orígenes urbanos), Sevilla: Junta de Andalucía, Consejería de Cultura y Medioambiente.

Mena García, C. (1984): La sociedad de Panamá en el siglo XVI, Sevilla: Diputación de Sevilla, Servicio de Publicaciones.

Molina, J. L. (2005): "El estudio de las redes personales: Contribuciones, métodos y perspectivas", Empiria, 10: Julio-Diciembre, pp. 71-106.

Mowshowitz, A. y Dehmer, M. (2012): "Entropy and the Complexity of Graphs Revisited", Entropy, Vol. 13, N. 3, pp. 559-570.

Oтте, E. (2004): “Diego Caballero, funcionario de la Casa de la Contratación”, en E. Vila Vilar, A. Acosta Rodríguez, y A. L. González Rodríguez (coords.), La Casa de la 
Contratación y la Navegación entre España y las Indias, Sevilla: Universidad de Sevilla. pp. 315-339,

Ribeiro, A. S. (2016): Early Modern Trading Networks in Europe. Cooperation and the Case of Simon Ruiz, Londres: Routledge.

Sмітн, R. S. (1972): The Spanish Gild Merchant: A History of the Consulado, 1250-1700, New York.

Tovar, H. (1999): Lo medieval en la conquista y otros ensayos americanos. Madrid.

VARÓn Gabai, R. (1994): "Negocios y gobierno de los Pizarro del Perú. Un ensayo de interpretación”, Histórica, Vol. XVIII, N. 2, pp. 417-433.

Varón Gabai, R. (1989): "Los dueños del Perú: Negocios e inversiones de los Pizarro en el siglo XVI", Histórica, Vol. XIII, N. 2, pp. 197-242.

VILAR, P. (1974): Oro y moneda en la Historia, 1450-1920. $3^{\text {a }}$ Edición, Barcelona.

Wasserman, S. y Faust, K. (2012): Social Network Analysis. Methods and Applications, Londres: Cambridge University Press. 